2

3 Running title:

4 MtMOT1.2 delivers Mo to nodules

5

6

7 Corresponding author:

8 Manuel González-Guerrero

9 Centro de Biotecnología y Genómica de Plantas (UPM_INIA)

10 Universidad Politécnica de Madrid

11 Campus de Montegancedo

12 Crta M-40, km 38

1328223 Pozuelo de Alarcón (Madrid)

14 Spain

15 Tel: +34 913364558

16 Email: manuel.gonzalez@upm.es

17

18 Manuel Tejada-Jiménez

19 Department of Biochemistry and Molecular Biology

20 Campus de Rabanales

21 Universidad de Córdoba

22 Córdoba, Spain.

23 Tel: +34957218352

24 Email: manuel.tejada@uco.es

Primary research area:

30

Membranes, Transport and Bioenergetics 


\section{MtMOT1.2 is responsible for molybdate supply to Medicago truncatula} nodules

36 Patricia Gil-Díez ${ }^{1}$, Manuel Tejada-Jiménez ${ }^{1,2}$, Javier León-Mediavilla ${ }^{1}$, Jiangqi Wen ${ }^{3}$,

37 Kirankumar S. Mysore ${ }^{3}$, Juan Imperial ${ }^{1,4}$, Manuel González-Guerrero ${ }^{1}$

${ }^{1}$ Centro de Biotecnología y Genómica de Plantas (UPM-INIA). Campus de 40 Montegancedo. Universidad Politécnica de Madrid. Crta. M-40 km 38. 28223 Pozuelo de 41 Alarcón (Madrid). Spain.

$42{ }^{2}$ Department of Biochemistry and Molecular Biology, Universidad de Córdoba, Campus 43 de Rabanales, Córdoba, Spain.

$44 \quad{ }^{3}$ Noble Research Institute, LLC., Ardmore, Oklahoma 73401.

$45{ }^{4}$ Instituto de Ciencias Agrarias, Consejo Superior de Investigaciones Científicas. Serrano, 46115 bis, 28006 Madrid. Spain.

One Sentence summary: MtMOT1.2 mediates molybdate transfer from the vasculature to nitrogen-fixing nodules

List of author contributions: P.G-D. carried out most of the experiments. Yeast transport assays were performed by M.T-J. J. L-M. studied the complementation with molybdate of the mot1.2-1 mutant. J.W. and K.S.M performed M. truncatula mutant screening and isolated the mot1.2-1 allele. M.T-J, J.I., and M.G-G. designed the experiments, analysed the data, and wrote the manuscript with input from all the other authors.

Funding information: This research was funded by a European Research Council Starting Grant (ERC-2013-StG-335284) and a Spanish Ministry of Economy and Competitiveness grant (AGL2015-65866-P) to M.G-G. Development of the $M$. truncatula Tnt1 mutant population was, in part, funded by the National Science Foundation, USA (DBI-0703285 \& IOS-1127155) to K.S.M. Yeast transport assays were partially funded by the Plan Propio de la Universidad de Córdoba (to M.T-J) and MINECO (BFU2015-70649-P).

64 
67

68

69

\section{ABSTRACT}

Symbiotic nitrogen fixation in legume root nodules requires a steady supply of molybdenum for synthesis of the iron-molybdenum cofactor of nitrogenase. This nutrient has to be provided by the host plant from the soil, crossing several symplastically disconnected compartments through molybdate transporters, including members of the MOT1 family. MtMOT1.2 is a Medicago truncatula MOT1 family member located in the endodermal cells in roots and nodules. Immunolocalization of a tagged MtMOT1.2 indicates that it is associated to the plasma membrane and to intracellular membrane systems, where it would be transporting molybdate towards the cytosol, as indicated in yeast transport assays. A loss-of-function mot1.2-1 mutant showed reduced growth compared to wild-type plants when nitrogen fixation was required, but not when nitrogen was provided as nitrate. While no effect on molybdenum-dependent nitrate reductase activity was observed, nitrogenase activity was severely affected, explaining the observed difference of growth depending on nitrogen source. This phenotype was the result of molybdate not reaching the nitrogen-fixing nodules, since genetic complementation with a wild-type MtMOT1.2 gene or molybdate-fortification of the nutrient solution, both restored wild-type levels of growth and nitrogenase activity. These results support a model in which MtMOT1.2 would mediate molybdate delivery by the vasculature into the nodules.

(1)


Symbiotic nitrogen fixation carried out by the legume-rhizobia partnership is one of the main sources of assimilable nitrogen in natural ecosystems and in sustainable agriculture (Downie, 2014). The symbiosis is established in differentiated root organs, the nodules, developed after a complex chemical exchange between the symbionts (Oldroyd, 2013). Nodule inner cells are infected by rhizobia in an endocytic-like process that results in organelle-like structures, the symbiosomes (Vasse, 1990; Limpens et al., 2009). There, surrounded by a plasmalemma-derived membrane, the symbiosome membrane, rhizobia will differentiate into nitrogen-fixing bacteroids (Roth, 1989, Vasse, 1990). As a result, dedicated membrane transporters would be required to transfer the

111 fixed nitrogen to the host plant, while the bacteroid receives photosynthates and mineral nutrients (Udvardi and Poole, 2013).

Transition metal nutrients, such as iron $(\mathrm{Fe})$, copper $(\mathrm{Cu})$, zinc $(\mathrm{Zn})$, or molybdenum (Mo), are required in relatively large amounts for symbiotic nitrogen fixation (O’Hara, 2001; Brear et al., 2013; González-Guerrero et al., 2014). While Fe, $\mathrm{Cu}$, and $\mathrm{Zn}$ are employed as cofactors of multiple enzymes present in the nodule (Brear et al., 2013; González-Guerrero et al, 2014), Mo is required by just two when nitrogen

118 fixation is active. One of them is a xanthine dehydrogenase that might be required for nitrogen delivery out of the nodules (Kaiser et al., 2005); while the other is nitrogenase, the protein complex directly responsible for converting $\mathrm{N}_{2}$ into $\mathrm{NH}_{4}{ }^{+}$by the bacteroids. In this enzyme, Mo is a key element of its unique Fe-Mo cofactor (FeMoco) (Rubio and Ludden, 2005). Consequently, Mo uptake and delivery to the nodules is an essential process for legumes and for symbiotic nitrogen fixation.

Mo is present in soil as molybdate, a close structural analogue to sulfate (Stiefel, 2002). In fact, for many years it was believed that molybdate was mainly transported by sulfate carriers, since, under the right conditions, they can also carry molybdate across membranes (Stout et al., 1951; Mendel and Hansch, 2002; Kaiser et al., 2005). However, more recently, molybdate-specific transporters have been identified (Tejada-Jiménez et al., 2007; Tomatsu et al., 2007; Tejada-Jiménez et al., 2011). Among them, the better known is the MOT1 family of transporters (Tejada-Jimenez et al., 2007; Tomatsu et al., 2007; Baxter et al., 2008). These proteins are evolutionarily related to sulfate transporters of the SULTR family (Tejada-Jimenez et al., 2007). However, the conserved STAS domain common to the latter proteins is not present in the MOT1 family members, which are characterized by the domains: P-PVQPMKXIXA-A and FG-MP-CHGAGGLA-QY- 
135 FGGR-G (Tejada-Jimenez et al., 2007). In Arabidopsis, two MOT1 genes have been 136 found: AtMOT1, involved in Mo uptake (Tomatsu et al., 2007; Baxter et al., 2008); and 137 AtMOT2, associated to the vacuole, and playing a role in inter-organ molybdate allocation 138 (Gasber et al., 2011).

139 On an average, legume genomes encode more copies of MOT1 gene family 140 members than other dicots. This could be the result of evolutionary pressures to expand 141 this family to account for the increased demand of Mo in symbiotic nitrogen fixation 142 (O'Hara et al., 2001). For instance, Glycine max has seven members; Phaseolus vulgaris, four; and Medicago truncatula has five (MtMOT1.1 to MtMOT1.5). Two legume MOT1

144 proteins have been characterized to date (Gao et al., 2016; Duan et al., 2017; Tejada145 Jimenez et al., 2017). LjMOT1 would be responsible for molybdate uptake from soil and 146 its distribution to plant sink organs (Gao et al., 2016; Duan et al., 2017), in a role similar 147 to that played by AtMOT1 (Tomatsu et al., 2007). This is indicated by the expression of 148 this transporter in the epidermis and in the root vasculature, as well as by the reduction 149 of Mo content in nodules and leaves in mutant plants (Duan et al., 2017). However, 150 LjMOT1 would not primarily be involved in molybdate delivery to the nodules, since lack of this transporter has no significant effect on nitrogen fixation capabilities. In contrast, mutation of the other characterized legume MOT1 protein, nodule-specific MtMOT1.3, results in nearly a total loss of nitrogenase activity (Tejada-Jiménez et al., 2017). Immunolocalization of this transporter in the plasma membrane and characterization of its transport capabilities indicate that its main function would be introducing molybdate into nodule cells. However, mot1.3-1 mutant nodules still accumulate more Mo than wild-type ones, suggesting that the delivery of this metal to the nodules is not impaired by MtMOT1.3 mutation (Tejada-Jiménez et al., 2017). Consequently, we still need to identify the transporters responsible for molybdate release from the vasculature into the nodules. This function would require two types of transporters: a MOT1-like for uptake from the vessels, and a yet-to-be-defined molybdate efflux protein (perhaps a sulfate transporter) to extrude Mo into the nodule apoplast.

Among the four remaining MOT1 transporters in M. truncatula, MtMOT1.1 is the most closely related to LjMOT1, and would likely play a similar role (Tejada-Jiménez et al., 2017). MtMOT1.4 and MtMOT1.5 are expressed all over the plant, while MtMOT1.2 is the only one of these four genes that is expressed exclusively in roots and nodules, with a maximum of expression in the latter (Tejada-Jimenez et al., 2017). Here, we characterize the function of MtMOT1.2 as a likely candidate for molybdate uptake from 
169 the vasculature by endodermal cells. MtMOT1.2 is located in the endodermis of nodule

170 and root vascular cylinders, in the plasma membrane and in an endomembrane

171 compartment. It shows molybdate uptake capabilities in yeast, and its mutation in $M$.

172 truncatula leads to a reduction in nitrogenase activity in nodules, likely the result of the

173 reduction in molybdate delivery to the nodules. Its function seems to be relevant for

174 symbiotic nitrogen fixation, with no major role being played under non-symbiotic

175 conditions, given how its mutation has no effect on plants grown on nitrate or on nitrate

176 reductase activity. This work represents a further step towards understanding how

177 molybdate in particular, and transition metals, in general, are delivered to legume nodules,

178 and represents the first case in which a metal transporter has been associated with root-

179 to-nodule vascular metal delivery.

180

181 RESULTS

182

MtMOT1.2 is a molybdate transporter

It has been reported that proteins belonging to MOT1 family are involved in the transport of the oxyanion molybdate into the cytosol of cells (Tejada-Jimenez et al., 2013). Members of MOT1 family showed a high sequence similarity to other molybdate transporters, including the signature motives of MOT1 family (Tejada-Jimenez et al., 2007). To confirm that MtMOT1.2 was able to transport molybdate, a yeast expression system was used, since these Saccharomyces cerevisiae is among the rare organisms lacking Mo-containing proteins and having no Mo transporters (Mendel and Bittner, 2006). When grown in the presence of molybdate, yeast expressing MtMOT1.2 were able to accumulate Mo following a Michaelian kinetics (Fig. 1A), with a $V_{\max }$ of $155 \pm 12$ pmol $10^{-6}$ cells h$^{-1}$ and a $k_{1 / 2}$ of $488 \pm 105 \mathrm{nM}$. This transport was not inhibited by the structural analogue sulfate, even at concentrations up to 4,000 times higher (Fig. 1B).

MtMOT1.2 is located in the plasma membrane and intracellular compartments in the endodermal/periccle layer in roots and nodules

According to Symbimics database (https://iant.toulouse.inra.fr/) (Roux et al., 2014) and previously reported data (Tejada-Jiménez, 2017), MtMOT1.2 is expressed in nodules and roots of $M$. truncatula. In order to identify the tissues in which its expression peaks, $1,446 \mathrm{bp}$ upstream of the start codon of MtMOT1.2 were fused to a $\beta$ - 
202 glucuronidase (gus) gene. M. truncatula plants were transformed with this genetic construct and GUS activity was visualized at 28 days-post-inoculation (dpi). The results confirmed that MtMOT1.2 was expressed in nodules and roots (Fig. 2A). Root sections showed that most of the GUS activity was confined to the endodermal layer around the root vessels (Fig. 2B). Similarly, MtMOT1.2 expression in the nodules was located around the nodule vasculature (Fig. 2C), and no expression was observed in the inner nodule regions, even when they were clarified with bleach (Supplemental Fig. S1).

Immunolocalization of MtMOT1.2 was performed by fusing the full genomic region (comprising from 1,446 bp upstream of the start codon to the last codon before the 212 stop) to three hemagglutinin (HA) epitopes. Localization of the MtMOT1.2-HA protein 213 was carried out with a mouse anti-HA primary antibody and a secondary anti-mouse 214 Alexa594-conjugated antibody. The plants were inoculated with a S. meliloti strain 215 constitutively expressing green fluorescent protein (GFP), and DNA was stained blue 216 with 4'-6-diamino-phenylindole (DAPI). The result of this staining showed that 217 MtMOT1.2-HA was located in a cell layer around the root and nodule vessels (Fig. 3A 218 and B), thus validating the gus-reporter assays. The detection of autofluorescence bands 219 corresponding to the Casparian strip suggests that these cells form the endodermis of the 220 nodule vessels (Supplementary Fig. S2). The Alexa594 signal was observed in two 221 locations within a cell: in the periphery of the cells and in a perinuclear region (Fig. 3A). 222 In the root, MtMOT1.2-HA had a similar cellular distribution (Fig. 3B). This pattern of 223 detection was not the result of autofluorescence detected in the Alexa594 emission channel, since negative controls with exactly the same conditions did not show any signal in this emission range (Supplemental Fig. S3).

To obtain further detail on the subcellular distribution of MtMOT1.2, Nicotiana benthamiana leaves were co-agroinfiltrated with a C-terminal GFP-tagged MtMOT1.2 and the plasma membrane-marker AtPIP2 labelled with cyan fluorescent protein (CFP). Figure $3 \mathrm{C}$ shows that both signals co-localize, indicating that in $N$. benthamiana

230 MtMOT1.2 is located in the plasma membrane. Again, these signals were not due to autofluorescence, since neither GFP nor CFP were detected in leaves expressing just AtPIP2-CFP, or MtMOT1.2-GFP, respectively (Supplemental Fig. S4). MtMOT1.2-HA localization was also determined with transmission electron microscopy and a goldconjugated secondary antibody (Fig. 3D). In these sections, the epitope was detected in the plasma membrane and in an intracellular membrane compartment, likely the 
236 endoplasmic reticulum. No gold particles were detected in control nodules (Supplemental

237 Fig. S5).

238

MtMOT1.2 is required for molybdate delivery to nitrogen fixing root nodules

A M. truncatula Transposable Element from N. tabacum (Tnt1) insertion lines (Tadege et al., 2008) were used for a reverse genetics screening (Cheng et al., 2011; 242 Cheng et al., 2014) to identify a mutant line (NF9961, mot1.2-1) carrying Tnt1 in MtMOT1.2 to determine the physiological role of MtMOT1.2. Tnt-1 insertion in the mutant mot1.2-1 is located in the second exon of the gene, 1,576 bp downstream of the start codon (Fig 4A). No MtMOT1.2 transcript was detected by RT-PCR in either roots or nodules of mot1.2-1 (Fig. 4B). Since MtMOT1.2 was expressed in roots of plants inoculated and non-inoculated with $S$. meliloti, mot1.2-1 phenotype was assessed under both conditions.

When the plants received an assimilable form of nitrogen $\left(\mathrm{KNO}_{3}\right)$ in their nutrient solution, and no $S$. meliloti inoculum was added, no significant differences in growth (Fig. 4C) or in biomass production (Fig. 4D) were observed between wild-type and mutant plants. Since nitrate was the sole nitrogen source for these plants, they would require the activity of the Mo-containing enzyme nitrate reductase to grow (Bernard and Habash, 2009), and any deffect on Mo uptake or source-to-sink delivery in these plants would lead to a reduction of Mo-dependent enzymatic activities. However, nitrate reductase activity in mot1.2-1 plants watered with $\mathrm{KNO}_{3}$ was equivalent to that of wild-type plants (Fig. 4E). No significant change was observed even when no molybdate was added to the nutrient solution (Supplemental Fig. S6).

In contrast, under symbiotic conditions, when the plant depends on symbiotic nitrogen fixation as the sole source of nitrogen, mot1.2-1 plants showed reduced growth when compared to the controls (Fig. 5A), with smaller nodules (Fig. 5B) and a biomass reduction of 54\% and 38\% in shoot and root, respectively (Fig. 5C). The reduction of growth and nodule size did not seem to be the consequence of alterations on nodule development, or deffects in nodulation kinetics (neither the number of nodules per plant, nor the rate of nodulation were affected; Supplemental Fig. S7). Growth reduction in mot1.2-1 plants is the likely result of a reduction of nitrogenase activity in those nodules, which was only $12 \%$ of that in wild-type plants (Fig. 5D). Mutant nodules exhibited a significant reduction in Mo content, while no significant changes were observed in roots 
mot1.2-1 with MtMOT1.2-HA improved growth and restored wild-type levels of nitrogenase activity (Fig. 5). Similarly, increasing molybdate content in the nutrient solution restored wild-type growth and nitrogenase activity in mot1.2-1 nodules (Supplemental Figure S8).

\section{DISCUSSION}

Mo is an essential oligonutrient for plants. As part of the Mo cofactor (Moco), it is used by five different proteins: i) Nitrate reductase (NR), for the reduction of nitrate to nitrite, a key step in the inorganic nitrogen assimilation process; ii) sulfite oxidase (SO), which oxidizes sulfite to sulfate producing hydrogen peroxide and thus has a role in ROS production; iii) aldehide oxidase (AO), which is related with the production of abscisic acid and auxin; iv) xanthine dehydrogenase (XDH), which catalyses hydroxylation of aldehydes and aromatic heterocycles in the purine degradation metabolic pathway; and $\mathrm{v}$ ) the amidoxime reducing component (ARC), which catalyse the reduction of $\mathrm{N}$ hydroxylated products (Mendel and Bittner, 2006; Hille et al., 2001). Consequently, plants need a regular supply of this nutrient from soil to sink organs. Mo requirements by legumes are substantially higher that those of other dicots (Clark, 1984; Tisdale et al., 1985), as a result of the synthesis of large quantities of nitrogenase by rhizobia in their root nodules (Miller et al., 1993). These bacteria use Mo to synthesize FeMoco required for nitrogenase activity (Rubio and Ludden, 2008). While much is known on how Moco and FeMoco are synthesized (Rubio and Ludden, 2008; Mendel, 2013) much less is known on how Mo is ferried to the enzymes synthesizing each cofactor. A major breakthrough has been the identification of molybdate-specific transporters (TejadaJimenez et al., 2013), such as those of the MOT1 family (Tejada-Jimenez et al., 2007; Tomatsu et al., 2007) and the description of the role of these proteins in molybdate uptake from soil in Arabidopsis and in L. japonicus (Tomatsu et al., 2007; Baxter et al., 2008; Duan et al., 2017). More recently, a MOT1 protein has been reported as responsible for molybdate uptake by sink organ cells in $M$. truncatula nodules, participating in symbiotic nitrogen fixation (Tejada-Jimenez et al., 2017). However, how Mo reaches this sink organ still remains obscure.

MtMOT1.2 is a M. truncatula MOT1 family member that is expressed in roots and nodules (Tejada-Jimenez et al., 2017). All MOT1 members identified so far have shown Mo transport activity (Tejada-Jiménez et al., 2007; Tomatsu et al., 2007; Baxter et al., 
assays confirm that MtMOT1.2 is able to transport molybdate, showing kinetic parameters comparable to those of previously characterized MtMOT1.3 and LjMOT1 transporters (Duan et al., 2017; Tejada-Jimenez et al., 2017), with lower affinity and higher speed than MOT1 proteins from Chlamydomonas reindhartii and A. thaliana

308 (Tejada-Jimenez et al., 2007; Tomatsu et al., 2007). This difference could be due to a 309 higher local concentration of molybdate in nodules corresponding to the increased Mo demand of these organs, for which a low-affinity system would be enough, but that would need to work at higher rates. In spite of its relatively low molybdate affinity, MtMOT1.2 is a transporter specific for this anion, since the addition of up to a 4,000-fold excess of the structurally similar anion sulfate did not inhibit Mo transport.

Within roots and nodules MtMOT1.2 expression was detected around the vessels, as indicated by promoter::gus fusions and immunolocalization of a HA-tagged version of the protein. More specifically, the tagged protein could be detected in endodermal cells in both nodule and root vessels. As it was the case for $A$. thaliana MOT1 (Tomatsu et al., 2007), MtMOT1.2-HA was observed in the plasma membrane and in an endodermal compartment resembling the endoplasmic reticulum. This could indicate a role in introducing molybdate into the cytosol, either from the cell exterior or from intracellular reserves. Alternatively, the endoplasmic reticulum subpopulation of MtMOT1.2 could also correspond to newly synthesized protein being ferried towards the plasma membrane. Surprisingly for a vascular transporter, no polar localization in the cell was observed. Molybdate could be introduced into the cell from the apoplast or from the vessels. As a result, in the abscense of another driving force, it would result in a futile cycle in which no net transfer of molybdate from sink to source would occur. Since this is not what happens, molybdate is being delivered from root to nodules, it might be speculated that molybdate delivery could be driven by a net mass-effect in which the molybdate pulled from the nitrogen-fixing cells, with their high molybdate uptake capability for FeMoco synthesis, would prevent a backward flux of Mo. The net transport into rhizobia-infected cells would have to be driven by transforming molybdate into different chemical species, rather than a substrate MOT1 proteins. Such a system would also ensure that should Mo not be used and accumulated in a given compartment, it would be rapidly recycled back for use elsewhere.

The localization of MtMOT1.2 in the vasculature and its function in molybdate uptake into the cell is suggestive of a role in the sink-to-source transport of this oligonutrient. Its position in the root endodermis indicates that it would be facilitating the 
338 transfer of apoplastic molybdate to the vasculature, so that molybdate would then be transferred to leaves or nodules. However, our data indicate that MtMOT1.2 does not play an essential role in molybdate transport to the leaves, since mutant plants in this gene did not have any significant growth alteration compared to wild-type plant, and, more importantly, Mo-dependent nitrate reductase activity was not affected in mot1.2-1 when nitrate was the sole nitrogen source to these plants. In contrast, when plants relied on symbiotic nitrogen fixation for assimilable nitrogen, mot1.2-1 plants showed a severe growth defect. This difference in growth between the two different nutritional situations could be the result of two non-incompatible possibilities: i) MtMOT1.2 is functionally substituted by another molybdate transporter in roots when mutated, and ii) MtMOT1.2 is only essential for molybdate release to the nodule. The endodermal localization in nodule vessels and the predicted direction of transport is indicative of a role in introducing the molybdate delivered by the vessels into endodermal cells. This would be the first step towards transferring molybdate to the nodule apoplast for uptake by MtMOT1.3. The plant growth defect observed in nitrogen-fixing conditions arises from the reduction of nitrogenase activity in these plants, consequence of insufficient molybdate reaching the nitrogen-fixing cells, as indicated by the lower levels of Mo in the mot1.2-1 nodules and the restoration of the wild-type phenotype when more Mo was added to the nutrient solution. The pattern of Mo accumulation in mot1.2-1 plants compared to their controls, with no significant changes in roots and a decrease in nodules, indicates that the defect in molybdate delivery for nitrogen fixation is occurring at the level of nodule vessels and not in loading the root vasculature with Mo. Otherwise, an accumulation of Mo in mot1.2 roots would be expected as well as a decrease in shoots, and none was detected in either (in this case, even slightly higher levels were detected).

In summary, MtMOT1.2 would position itself between molybdate root uptake transporter, likely MtMOT1.1 as the closest LjMOT1 orthologue, and the nodule apoplast molybdate uptake protein MtMOT1.3 (Fig. 6). MtMOT1.2 would facilitate the transfer of this oligonutrient into endodermal cells mediating the sink-to-source molybdate trafficking, which would be controlled by mass-effects to ensure that it reaches its destination. However, a critical point remains to be solved, which is the identity of the proteins mediating molybdate efflux from the cytosol to the symbiosome. Whether these are sulfate transporters, or whether a novel family of Mo transporters with a direction of transport opposite to MOT1 proteins, remains to be unveiled. 


\section{METHODS}

\section{Biological material and growth conditions}

M. truncatula R108 seeds were scarified by incubating with concentrated sulfuric acid for $7 \mathrm{~min}$. After several washes with cold water, the seed surfaces were sterilized in $50 \%(\mathrm{v} / \mathrm{v})$ bleach for $90 \mathrm{~s}$, and left in sterile water in the dark overnight, followed by a $48 \mathrm{~h}$ incubation at $4{ }^{\circ} \mathrm{C}$. Seed germination was done in water-agar plates $0.8 \%(\mathrm{w} / \mathrm{v})$.

378 Seedlings were planted in sterile perlite pots, and inoculated with Sinorhizobium meliloti 3792011 or the same bacterial strain transformed with pHC60 (Cheng and Walker, 1998).

380 Plants were grown in a greenhouse with $16 \mathrm{~h}$ of light and $22^{\circ} \mathrm{C}$, and watered every two days with Jenner's solution or water alternatively (Brito et al., 1994). Nodule collection was carried out at 28 dpi. Non-nodulated plants were supplemented every two weeks with $2 \mathrm{mM} \mathrm{KNO}_{3}$, instead of being inoculated with S. meliloti 2011. For hairy root transformation of M. truncatula seedlings, Agrobacterium rhizogenes strain ARqual having the appropriate vector was used (Boisson-Dernier et al., 2001). Agroinfiltration experiments for transitory expression were done in $N$. benthamiana leaves using $A$. tumefaciens $\mathrm{C} 58 \mathrm{C} 1$ as a vector for the corresponding genetic construct. $N$. benthamiana plants were grown in the greenhouse under the same conditions as M. truncatula.

In heterologous expression assays the yeast $S$. cerevisiae strain $31019 \mathrm{~b}$ (MATa ura3 mep1 mep2 $\triangle:: L E U 2$ mep3A:: KanMX2) was used (Marini et al., 1997). Yeasts were grown in synthetic dextrose (SD) or yeast peptone dextrose (YPD) medium supplemented with $2 \%$ glucose (Sherman et al., 1986).

\section{Molybdate uptake}

$S$. cerevisiae cells grown in SD medium were transferred to $10 \mathrm{mM}$ MES-Ca(OH $)_{2}$ uptake was measured after $30 \mathrm{~min}$ incubation at $28^{\circ} \mathrm{C}$ in the presence of $500 \mathrm{nM}$ $\mathrm{Na}_{2} \mathrm{MoO}_{4}$. For molybdate transport kinetics yeast cells were transferred to the same MES buffer supplemented with 100, 200, 500, 1000 and $2000 \mathrm{nM} \mathrm{Na}_{2} \mathrm{MoO}_{4}$ and incubated for

$40030 \mathrm{~min}$ at $28{ }^{\circ} \mathrm{C}$. Molybdenum determination was carried out in $10 \mathrm{~mL}$ cell-free MES buffer using the method previously described (Cardenas and Morteson, 1975)

\section{GUS Staining}

A transcriptional fusion between MtMOT1.2 promoter region and the gus gene was obtained by amplifying $1.4 \mathrm{~kb}$ upstream of the MtMOT1.2 start codon using the 

nodule sections was carried out with a $50 \%$ bleach treatment for $30 \mathrm{~min}$.

\section{Immunohistochemistry and confocal microscopy}

Plasmid pGWB13 (Nakagawa et al., 2007) was used to clone a DNA fragment containing MtMOT1.2 full gene and 1,446 kb upstream of its start codon using Gateway epitopes in frame to MtMOT1.2. M. truncatula root transformation was carried out as indicated above. Transformed plants were inoculated with S. meliloti 2011 containing plasmid pHC60 that constitutively expresses GFP. Nodules and roots, collected at $28 \mathrm{dpi}$, were fixed in $4 \%(\mathrm{w} / \mathrm{v})$ paraformaldehyde and $2.5 \%(\mathrm{w} / \mathrm{v})$ sucrose in phosphate-buffered saline (PBS) at $4{ }^{\circ} \mathrm{C}$ and left overnight. Fixed plant material was sectioned with a Vibratome 1000 Plus (Vibratome), in $100 \mu \mathrm{m}$ sections. Dehydration of the sections was performed by incubation with methanol dilution series $(30 \%, 50 \%, 70 \%$ and $100 \%$ in PBS) for $5 \mathrm{~min}$ and then rehydrated following the same methanol series in reverse order. Cell wall permeabilization was done by incubating with $2 \%(\mathrm{w} / \mathrm{v})$ cellulase in PBS for 1 $\mathrm{h}$, and $0.1 \%(\mathrm{v} / \mathrm{v})$ Tween 20 in PBS for $15 \mathrm{~min}$. Bovine serum albumin 5\% (w/v) was used to block the sections. As primary antibody, a 1:50 dilution in PBS of anti-HA mouse monoclonal antibody (Sigma) was used. This dilution was incubated with the sections for $2 \mathrm{~h}$ at room temperature and then washed away three times with PBS for $10 \mathrm{~min}$. Secondary antibody used was 1:40 Alexa594-conjugated anti-mouse rabbit monoclonal antibody (Sigma) in PBS. The incubation was performed at room temperature for $1 \mathrm{~h}$ and then sections were washed three times with PBS for $10 \mathrm{~min}$. DNA was stained using DAPI. Images were obtained with a confocal laser-scanning microscope (Leica SP8).

\section{Gold-immunohistochemistry and electron microscopy}

Plants were transformed with plasmid pGWB13 containing MtMOT1.2 full gene and $1,446 \mathrm{bp}$ upstream of its start codon. Transformed plants were inoculated with $S$. meliloti 2011. Nodules were collected at $28 \mathrm{dpi}$ and were fixed in $1 \%$ formaldehyde and $0.5 \%$ glutaraldehyde in $50 \mathrm{mM}$ potassium phosphate $(\mathrm{pH} \mathrm{7.4)}$ for $2 \mathrm{~h}$. After that the 
440 phosphate $(\mathrm{pH} 7.4) 3$ times during $30 \mathrm{~min}$ and 3 times for $10 \mathrm{~min}$. Nodules were

441 dehydrated by incubation with ethanol dilution series of $30 \%, 50 \%, 70 \%, 90 \%$ during

$44210 \mathrm{~min}, 96 \%$ for $30 \mathrm{~min}$ and $100 \%$ during $1 \mathrm{~h}$. Samples were included in a series of

443 ethanol and LR-white resin (London Resin Company Ltd, UK) dilutions: 1:3 during 3 h,

$444 \quad$ 1:1 were left overnight and 3:1 during $3 \mathrm{~h}$. Nodules were included in resin during $48 \mathrm{~h}$.

445 All the process was performed at $4{ }^{\circ} \mathrm{C}$. Nodules were placed in gelatine capsules and filled

446 with resin and polymerized at $60^{\circ} \mathrm{C}$ for $24 \mathrm{~h}$. One-micron thin sections were cut at Centro

447 Nacional de Microscopia Electrónica (Spain) with Reichert Ultracut S-ultramicrotome

448 fitted with a diamond knife. Thin sections were blocked in $2 \%$ bovine serum albumin in

449 phosphate buffer saline (PBS) for $30 \mathrm{~min}$. As primary antibody, a 1:20 dilution in PBS of

450 anti-HA rabbit monoclonal antibody (Sigma) was used. Samples were washed 10 times

451 in PBS for $2 \mathrm{~min}$. Secondary antibody used was 1:150 anti-rabbit goat conjugated to a 15

$452 \mathrm{~nm}$ gold particle (BBI solutions) diluted in PBS. Incubation was performed for $1 \mathrm{~h}$, after

453 that samples were washed 10 times in PBS for 2 min and 15 times in water for 2 min.

454 Sections were stained with $2 \%$ uranyl acetate and visualised in a JEM 1400 electron 455 microscope at $80 \mathrm{kV}$.

456

\section{Transient expression in Nicotiana benthamiana leaves}

458 Experiment was performed as is described by Wood et al (2009). GFP was fused 459 to the $\mathrm{C}$ terminus of MtMOT1.2 coding sequence by cloning it into pGWB5 (Nakagawa 460 et al., 2007) by Gateway cloning technology (Invitrogen). Four-week-old N. benthamiana 461 leaves were injected with A. tumefaciens C58C1 (Deblaere et al., 1985) cells 462 independently transformed with MtMOT1.2-GFP, with the plasma membrane marker 463 pm-CFP pBIN (Nelson et al., 2007) or with the silencing suppressor p19 of Tomato bushy 464 stunt virus (Wood et al., 2009). Expression in the leaves was analyzed after $3 \mathrm{~d}$ by 465 confocal laser-scanning microscopy (Leica SP8).

\section{$467 \quad$ Nitrogenase activity}

468 Nitrogenase activity was measured by the acetylene reduction assay (Hardy et al., 469 1968). 28 dpi wild-type and mutant plants were introduced in $30 \mathrm{ml}$ tubes and sealed with 470 rubber stoppers. Each tube contained at least four independently transformed plants. 10 $471 \%$ of the gas phase from each bottle was replaced by the same volume of acetylene. Tubes 472 were incubated for $30 \mathrm{~min}$ at room temperature. Ethylene production was measured by 
473 analyzing $0.5 \mathrm{ml}$ gas samples with a Shimadzu GC-8A gas chromatograph using a

474 Porapak N column (Shimadzu, Kyoto, Japan).

\section{Metal content determination}

Metal content was determined by inductively coupled plasma optical emission spectrometry in three sets of 28 dpi roots, shoots, and nodules, each set originating from a pool of five plants. The experiment was carried out at the Unit of Metal Analysis in the

480 Scientific and Technology Centers of the Universidad de Barcelona (Spain). These samples were digested with $\mathrm{HNO}_{3}, \mathrm{H}_{2} \mathrm{O}_{2}$ and $\mathrm{HF}$ in a Teflon reactor at $90{ }^{\circ} \mathrm{C}$. The sample was diluted with deionized water. Final volume was calculated by weight and weight: volume ratios. The samples were digested with three blanks in parallel. Metal determination was carried out in an Agilent $7500 \mathrm{cw}$ instrument under standard conditions. Calibration was carried out with five solutions prepared from certified NIST standards.

Nitrate reductase activity

489 Nitrate reductase activity was analyzed as described by Tejada-Jimenez et al 490 (2017). Briefly, a crude extract was obtained from approximately $100 \mathrm{mg}$ of fresh 491 material in $100 \mathrm{mM}$ potassium phosphate, $\mathrm{pH} 7.5,5 \mathrm{mM}$ magnesium acetate, $10 \%$ 492 glycerol (v/v), $10 \%$ polyvinylpolypyrrolidone (w/v), 0.1\% Triton X-100, 1 mM EDTA, $493 \quad 0.05 \%$ \% -mercaptoethanol and $1 \mathrm{mM}$ PMSF. Plant material was homogenized with liquid 494 nitrogen and 1:6 extraction buffer (v/v), and centrifuged at $14,000 \mathrm{xg}$ at $4{ }^{\circ} \mathrm{C}$ for $15 \mathrm{~min}$. 495 The reaction was started adding $50 \mu \mathrm{l}$ of crude extract to $0.5 \mathrm{ml}$ of reaction buffer and 496 incubated at $30^{\circ} \mathrm{C}$ for $20 \mathrm{~min}$. The reaction buffer contained $50 \mathrm{mM}$ potassium phosphate, $497 \mathrm{pH} 7.5,10 \mathrm{mM} \mathrm{KNO}_{3}, 5 \mathrm{mM}$ EDTA and $0.5 \mathrm{mM}$ NADH. The reduction reaction was 498 stopped by adding 1 volume of $1 \%$ sulfanilamide in $2.4 \mathrm{M} \mathrm{HCl}$, and 1 volume of $0.02 \%$

499 N-1-naphtyl-ethylenediamine. After centrifugation, the supernatant was collected and its 500 absorbance at $540 \mathrm{~nm}$ measured in a UV/visible spectrophotometer(Ultrospect 3300 pro; 501 Amersham Bioscience).

\section{Statistical analysis}

504 Student's unpaired $t$-test was used to calculate statistical significance of observed 505 differences. Test results with p-values less than 0.05 were considered as statistically 506 significant. 
507

508

509 (Universidad de Córdoba) for their help with the yeast transport assays, as well as to

510 members of Laboratory 281 at Centro de Biotecnología y Genómica de Plantas (UPM-

511 INIA) for their support and feed-back in preparing this manuscript.

512

513

514

515

516

517

518

519

520

521

522

523

524

525

526

527

528

529

530

531

532

533

534

535

536

537

538

539

540 
FIGURE LEGENDS

542 Figure 1. Medicago truncatula Molybdate Transporter 1.2 (MtMOT1.2) introduces 543 molybdate towards the cytosol. (A) Molybdate uptake by Saccharomyces cerevisiae 544 strain 31019b transformed with PDR196 vector containing MtMOT1.2 coding sequence 545 and grown at $28^{\circ} \mathrm{C}$. Values for the pDR196 empty vector were substracted from the data. 546 Data were fitted using Michaelis constant $\mathrm{k}_{1 / 2}=488 \pm 105 \mathrm{nM}$ and maximum speed $\mathrm{v}_{\max }=$ $155 \pm 12 \mathrm{pmol} 10^{6}$ cells $^{-1} \mathrm{~h}^{-1}$. Data are the mean \pm SD. (B) Effect of sulfate on molybdate uptake by $S$. cerevisiae strain 31019 b transformed with PDR196 containing the MtMOT1.2 coding sequence. Data sets consist of S. cerevisiae incubated with $500 \mathrm{nM}$ $\mathrm{Na}_{2} \mathrm{MoO}_{4}$ and $0,0.2$, or $2 \mathrm{mM} \mathrm{Na}_{2} \mathrm{SO}_{4}$. Data are the mean $\pm \mathrm{SD}$.

Figure 2. Medicago truncatula Molybdate Transporter 1.2 (MtMOT1.2) gene is expressed in the around the vessels in roots and nodules. (A) $\beta$-glucuronidase (GUS) staining of M. truncatula roots and nodules from 28 days-post-inoculation (dpi) plants transiently expressing the gus gene under the control of MtMOT1.2 promoter region. Scale bar $=0.5 \mathrm{~mm}$. (B) GUS activity localization in a cross section of a 28 dpi root from M. truncatula plants transiently expressing the gus gene under the control of MtMOT1.2 promoter region. Scale bar $=0.025 \mathrm{~mm}$. (C) GUS activity localization in a cross section of a 28 dpi nodule from M. truncatula plants transiently expressing the gus gene under the control of MtMOT1.2 promoter region. Scale bar $=25 \mu \mathrm{m}$.

Figure 3. Medicago truncatula Molybdate Transporter 1.2 (MtMOT1.2) is located in the plasma membrane and an endomembrane compartment in endodermal cells. (A) Crosssection of a 28 days-post-inoculation (dpi) M. truncatula nodule expressing MtMOT1.2$H A$ and inoculated with a Sinorhizobium meliloti strain constitutively expressing the green fluorescent protein (GFP) (green). MtMOT1.2-HA was detected using an Alexa594-conjugated antibody (red). DNA was stained with DAPI (blue). Left panel, localization of MtMOT1.2-HA; central panel, overlay with the green (S. meliloti)

569 channel; right panel, overlay of the central panel with the DAPI-stained DNA. Scale bars

$570=10 \mu \mathrm{m}$. (B) M. truncatula root expressing MtMOT1.2-HA. MtMOT1.2-HA was detected 571 using an Alexa594-conjugated antibody (red). DNA was stained with DAPI (blue). Left 572 panel, localization of MtMOT1.2-HA; central panel, overlay with the DAPI-stained DNA 573 and the xylem autoflorescence; right panel overlay with the transillumination image. 
574 Scale bars $=50 \mu \mathrm{m}$. (C) Transient co-expression of MtMOT1.3-GFP (green) and AtPIP2-

575 CFP (cyan) in Nicotiana benthamiana leaves. Left panel, AtPIP2-CFP signal, middle 576 panel MtMOT1.2-GFP signal; right panel overlay of the two channels with the 577 transillumination image. Scale bars $=25 \mu \mathrm{m}$. (D) Subcellular localization of MtMOT1.2-

578 HA in nodule vessels using a gold-conjugated anti-HA antibody. Arrowheads indicate the position of the gold particles. Scale bars $=250 \mathrm{~nm}$ and $500 \mathrm{~nm}$.

Figure 4. Medicago truncatula Molybdate Transporter 1.2 (MtMOT1.2) is not required for growth under non-symbiotic conditions. (A) Position of the Transposable element from Nicotiana tabacum1 (Tnt1) insertion within the MtMOT1.2 gene. (B) RT-PCR amplification of MtMOT1.2 coding sequence in 28 days-post-inoculation roots and nodules of M. truncatula wild type (WT) or mutant (mot1.2-1) plants. Ubiquitin carboxylterminal hydrolase1 (MtUbl) was used as a control. (C) Growth of representative WT and mot 1.2-1 plants watered with $\mathrm{KNO}_{3}$. Scale bar $=1 \mathrm{~cm}$. (D) Dry weight of shoots and roots. Data are the mean $\pm \mathrm{SD}$ of at least 6 independently transformed plants. (E) Nitrate reductase activity. Nitrate reduction was measured in duplicate. Data are the mean \pm SD.

Figure 5. Medicago truncatula Molybdate Transporter 1.2 (MtMOT1.2) is required for symbiotic nitrogen fixation. (A) Growth of representative WT, mot1.2-1, and mot1.2-1 transformed with MtMOT1.2-HA plants 28 days-post-inoculation (dpi). Scale bar $=1 \mathrm{~cm}$. (B) Detail of representative 28 dpi nodules from WT, mot 1.2-1, and mot1.2-1 transformed with MtMOT1.2-HA plants. Scale bars $=50 \mathrm{~mm}$. (C) Dry weight of shoots, and roots from 28 dpi WT, mot1.2-1, and mot1.2-1 transformed with MtMOT1.2-HA plants. Data are the mean \pm SD of at least 2 sets of 6 pooled independently transformed plants. (D)

598 Nitrogenase activity of 28 dpi WT, mot1.2-1, and mot1.2-1 transformed with MtMOT1.2$H A$ plants. Data are the mean $\pm \mathrm{SD}$ of 2 sets of 6 pooled plants. $100 \%=0.161 \mathrm{nmol}$ acetylene $\cdot \mathrm{h}^{-1}$ plant $^{-1}{ }^{*}$ indicates a statistically significant difference $(\mathrm{p}<0.05)$. (E) Mo content in shoots, roots, and nodules of WT, mot1.2-1, and mot1.2-1 transformed with MtMOT1.2-HA plants. Data are the mean \pm SD of at least 2 sets of 6 pooled independently transformed plants. ${ }^{*}$ indicates a statistically significant difference $(\mathrm{p}<0.05)$.

605 Figure 6 Model of molybdate transport in Medicago truncatula. Upper panel, molybdate 
607 perhaps MtMOT1.1. Symplastically and apoplastically-delivered molybdate will reach 608 the endodermis were MtMOT1.2 will introduce it from the apoplast. This role is not 609 carried out only by this protein, another molybdate transporter would also participate 610 delivering molybdate to the shoots. Molybdate efflux from the endodermis into the xylem 611 is mediated by a yet-to-be determined transporter. Lower panel, once molybdate reaches 612 the nodule, it is recovered from the vasculature by MtMOT1.2 that would introduce it 613 into the endodermal cells. Through an unknown protein, this molybdate is released into 614 the apoplast, where MtMOT1.3 will introduce it into nodule cells. SST1 and bacterial 615 ModABC would then direct the cytosolic molybdate to nitrogen-fixing bacteroids.

616

617

618

619

620

621

622

623

624

625

626

627

628

629

630

631

632

633

634

635

636

637

638

639

640 
REFERENCES

642

Baxter I, Muthukumar B, Park HC, Buchner P, Lahner B, Danku J, Zhao K, Lee J,

Hawkesford MJ, Guerinot ML, Salt DE (2008)Variation in molybdenum content across broadly distributed populations of Arabidopsis thaliana is controlled by a mitochondrial molybdenum transporter (MOT1). PLoS Genet. 4 (2): e1000004.

647

Bernard SM, Habash DZ (2009) The importance of cytosolic glutamine synthetase in (2001) Agrobacterium rhizogenes-transformed roots of Medicago truncatula for the study of nitrogen-fixing and endomycorrhizal symbiotic associations. Mol Plant Microbe Interact 14: 695-700.

655

Brear EM, Day DA, Smith PM (2013) Iron: an essential micronutrient for the legumerhizobium symbiosis. Front Plant Sci 4: 359

Brito B, Palacios JM, Hidalgo E, Imperial J, Ruiz-Argueso T (1994) Nickel availability to pea (Pisum sativum L.) plants limits hydrogenase activity of Rhizobium leguminosarum bv. viciae bacteroids by affecting the processing of the hydrogenase structural subunits. J Bacteriol 176: 5297-5303.

663

664 Cardenas J, Mortenson LE (1975) Role of molybdenum in dinitrogen fixation by 665 Clostridium pasteurianum. J Bacteriol 123 (3): 978-984.

666

667 Cheng HP, Walker GC (1998) Succinoglycan is required for initiation and elongation 668 of infection threads during nodulation of alfalfa by Rhizobium meliloti. J Bacteriol 180: $669 \quad 5183-5191$. truncatula using Tnt1 insertion mutants. Methods Mol Biol. 678: 179-190. 
674 Cheng X, Wang M, Lee HK, Tadege M, Ratet P, Udvardi M, Mysore KS, Wen J

675 (2014) An efficient reverse genetics platform in the model legume Medicago truncatula.

676 New Phytol. 201: 1065-1076.

677

678 Clark, R.B (1984) Physiological aspects of calcium, magnesium and molybdenum 679 deficiencies in plants. Soil Acidity and Liming 12 : 99-170.

680

681

Deblaere R, Bytebier B, De Greve H, Deboeck F, Schell J, Van Montagu M, Leemans

J (1985) Efficient octopine Ti plasmid-derived vectors for Agrobacterium-mediated gene transfer to plants. Nucleic Acids Res 13: 4777-4788.

684

685

Downie JA (2014) Legume nodulation. Curr. Biol. 24: R184-R190.

686

Duan G, Hakoyama T, Kamiya T, Miwa H, Lombardo F, Sato S, Tabata S, Chen Z,

Watanabe T, Shinano T, Fujiwara T (2017) LjMOT1, a high-affinity molybdate transporter from Lotus japonicus, is essential for molybdate uptake, but not for the delivery to nodules. Plant J 90: 1108-1119.

691

Gao JS, Wu FF, Shen SL, Meng Y, Cai YP, Lin Y (2016) A putative molybdate transporter LjMOT1 is required for molybdenum transport in Lotus japonicus. Physiol. Plant. 158: 331-340.

Gasber A, Klaumann S, Trentmann O, Trampczynska A, Clemens S, Schneider S, carrier critical for intracellular transport and inter-organ allocation of molybdate. Plant Biol 13: 710-718.

González-Guerrero M, Matthiadis A, Sáez A, Long TA (2014) Fixating on metals: new insights into the role of metal in nodulation and symbiotics nitrogen fixation. Front Plant Sci 5: 45. 
Hille R, Nishino T, Bittner F (2011) Molybdenum enzymes in higher organisms. Coord Chem Rev 225: 1179-1205.

710

711 Kaiser BN, Gridley KL, Ngaire BJ. Phillips T, Tyeman SD (2005) The role of

712 molybdenum in agricultural plant production. Ann Bot 96: 754-54.

714 Limpens E, Ivanov S, van Esse W, Voets G, Fedorova E. Bisseling T (2009) Medicago

$715 \mathrm{~N}_{2}$-Fixing symbiosomes acquire the endocytic identity marker Rab7 but delay the acquisition of vacuolar identity. Plant Cell 21: 2811-2828.

Marini AM, Soussi-Boudekou S, Vissers S, Andre B (1997) A family of ammonium

Mendel RR, Hansch R (2002) Molybdoenzymes and molybdenum cofactor in plants. J Exp Bot 53: 1689-1698.

Mendel RR, Bittner F (2006) Cell biology of molybdenum. Biochim Biophys Acta 1763: 621-635.

Mendel RR (2013) The molybdenum cofactor. J Biol Chem 288 (19): 13165-13172.

Miller RW, Yu Z, Zarkadas CG (1993) The nitrogenase proteins of Rhizobium meliloti: purification and properties of the MoFe and Fe components. Biochim Biophys Acta 1163: $31-41$. vectors, pGWBs, for realizing efficient construction of fusion genes for plant transformation. J Biosci Bioeng 104: 34-41. 
O'Hara GW (2001) Nutritional constraints on root nodule bacteria affecting symbiotic nitrogen fixation: a review. Aust. J. Exp. Agric. 41: 417-433

744 Oldroyd GED (2013) Speak, friend, and enter: signalling systems that promote beneficial symbiotic associations in plants. Nat Rev Micro 11: 252-263.

Roth LE, Stacey G (1989) Bacterium release into host cells of nitrogen-fixing soybean nodules: the symbiosome membrane comes from three sources. Eur J Cell Biol 49: 13-

Roux B, Rodde N, Jardinaud MF, Timmers T, Sauviac L, Cottret L, Carrere S, gene expression in symbiotic root nodules using laser-capture microdissection coupled to RNA sequencing. Plant J 77: 817-837.

Rubio LM, Ludden PW (2005) Maturation of nitrogenase: a biochemical puzzle. J. Bacteriol. 187: 405-414.

Rubio LM, Ludden PW (2008) Biosynthesis of the iron-molybdenum cofactor of nitrogenase. Annu. Rev. Microbiol. 62: 93-111.

Sherman F, Fink GR, Hicks JB (1986) Methods in yeast genetics. Plainview, NY: Cold Spring Harbor Lab Press.

Stiefel EI (2002) Molybdenum and tungsten: their roles in biological processes. In: Sigel A, Sigel H, eds. Metal ions in biological systems New York: Marcel Dekker Inc., 1-30.

Stout PR, Meagher WR, Pearson GA, Johnson CM (1951) Molybdenum nutrition of crop plants: I. The influence of phosphate and sulfate on the absortion of molybdenum from soils and solution cultures. Plant Soil 3: 51-87. 
774 the Tnt1 retrotransposon in the model legume Medicago truncatula. Plant Journal 54:

$775 \quad 335-347$.

776

Tejada-Jimenez M, Llamas A, Sanz-Luque, E, Galvan A, Fernandez E (2007) A high-affinity molybdate transporter in eukaryotes. Proc Natl Acad Sci U S A 104: 2012620130.

780

Tejada-Jiménez M, Galván A, Fernández E (2011) Algae and humans share a molybdate transporter. Proc Natl Acad Sci U S A 108: 6420-6425.

Tejada-Jimenez M, Gil-Diez P, León-Mediavilla J, Wen J, Mysore KS, Imperial J,

González-Guerrero M (2017) Medicago truncatula MOT1.3 is a plasma membrane molybdenum transporter required for nitrogenase activity in root nodules under molybdenum deficiency. New Phytol 216: 1223-1235.

Tisdale SL, Nelson WL, Beaton JD (1985) Soils fertility and fertilizers. New York, Macmillan, 4th edition: 188-239. Fujiwara T. (2007) An Arabidopsis thaliana high-affinity molybdate transporter required for efficient uptake of molybdate from soil. Proc Natl Acad Sci U S A 104: 18807-18812.

800 Udvardi M, Poole PS (2013) Transport and metabolism in legume-rhizobia symbioses.

801 Annu. Rev Plant Biol 64: 781-805.

802

803 Vasse J, de Billy F, Camut S, Truchet G (1990) Correlation between ultrastructural

804 differentiation of bacteroids and nitrogen fixation in alfalfa nodules. J Bacteriol 172: $805 \quad 4295-4306$. 
807 Vernoud V, Journet EP, Barker DG (1999) MtENOD20, a Nod factor-inducible

808 molecular marker for root cortical cell activation. Mol Plant Microbe Interact 12: 604809614.

810

811 Wood CC, Petrie JR, Shrestha P, Mansour MP, Nichols PD, Green AG, Singh SP

812 (2009). A leaf-based assay using interchangeable design principles to rapidly assemble 813 multistep recombinant pathways. Plant Biotechnol J 7: 914-924. 
bioRxiv preprint doi: https://doi.org/10.1101/272112; this version posted February 28, 2018. The copyright holder for this preprint (which was not certified by peer review) is the author/funder, who has granted bioRxiv a license to display the preprint in perpetuity. It is made available under aCC-BY-NC-ND 4.0 International license.

Figure 1

A

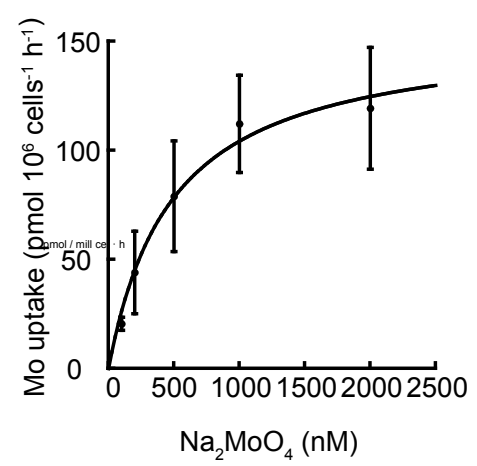

B

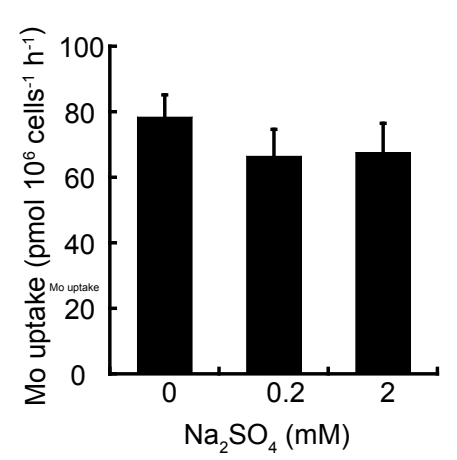


bioRxiv preprint doi: https://doi.org/10.1101/272112; this version posted February 28, 2018. The copyright holder for this preprint (which was not certified by peer review) is the author/funder, who has granted bioRxiv a license to display the preprint in perpetuity. It is made available under aCC-BY-NC-ND 4.0 International license.

\section{Figure 2}

A

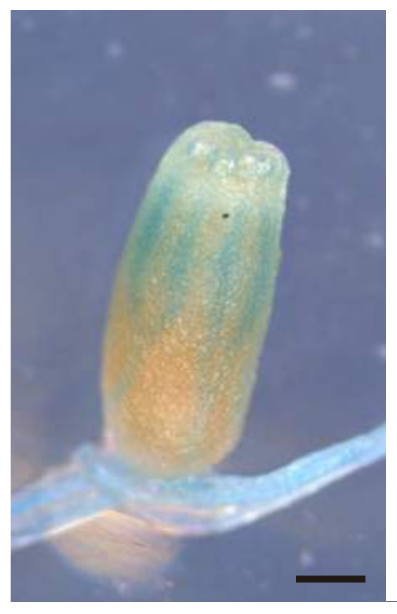

B

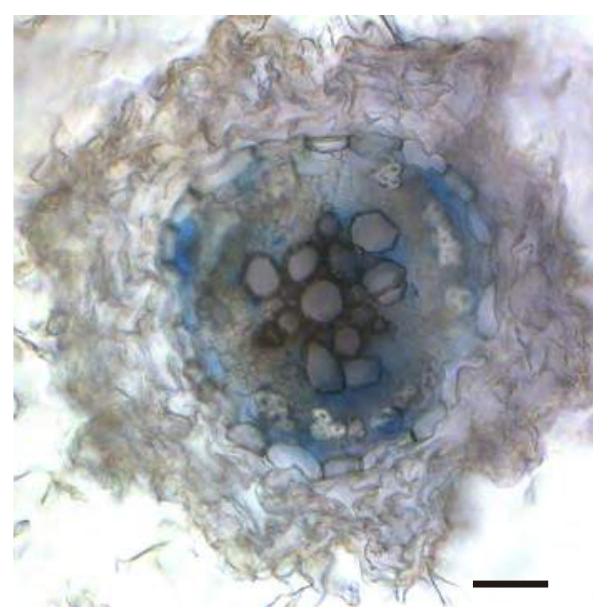

C

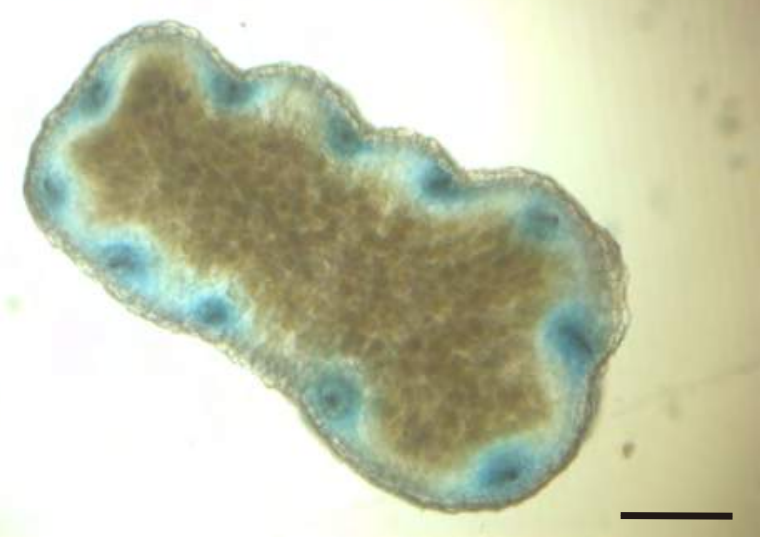


bioRxiv preprint doi: https://doi.org/10.1101/272112; this version posted February 28, 2018. The copyright holder for this preprint (which was not certified by peer review) is the author/funder, who has granted bioRxiv a license to display the preprint in perpetuity. It is made available under aCC-BY-NC-ND 4.0 International license.

Figure 3

A
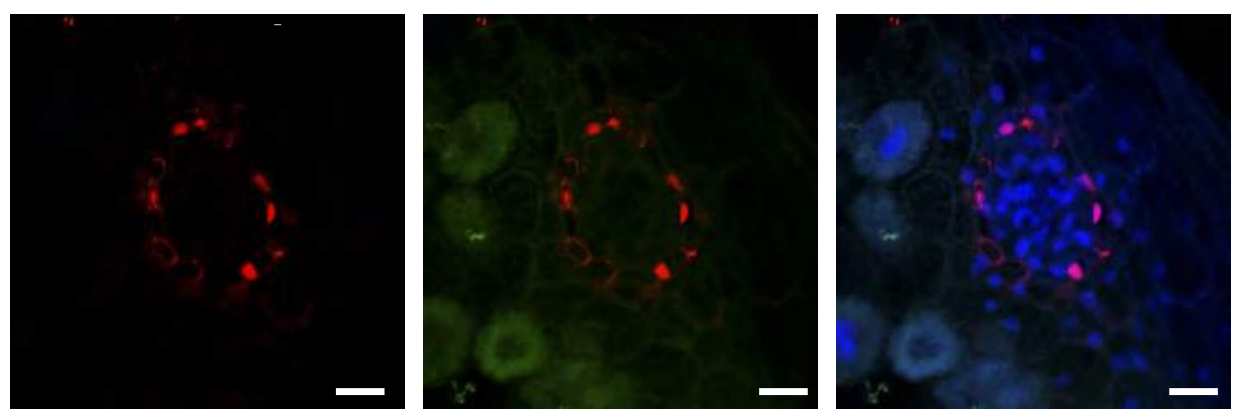

B
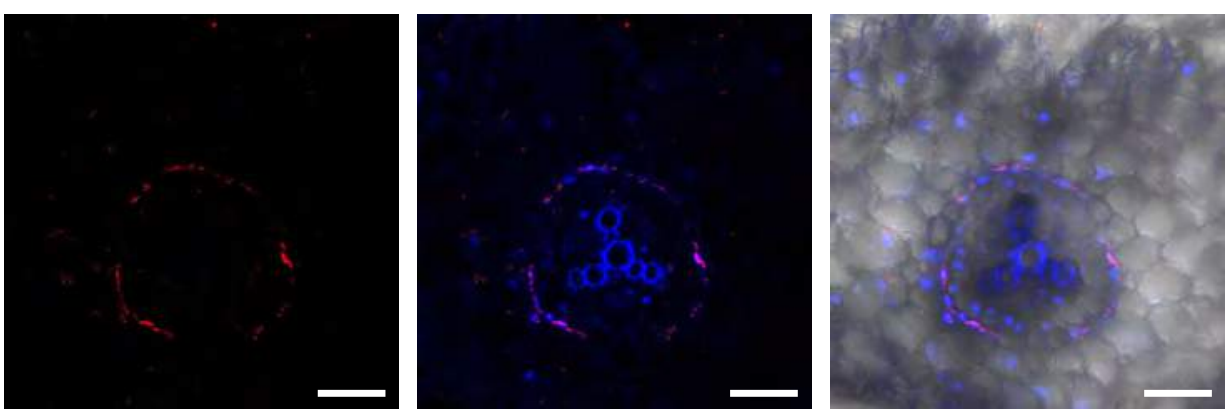

C
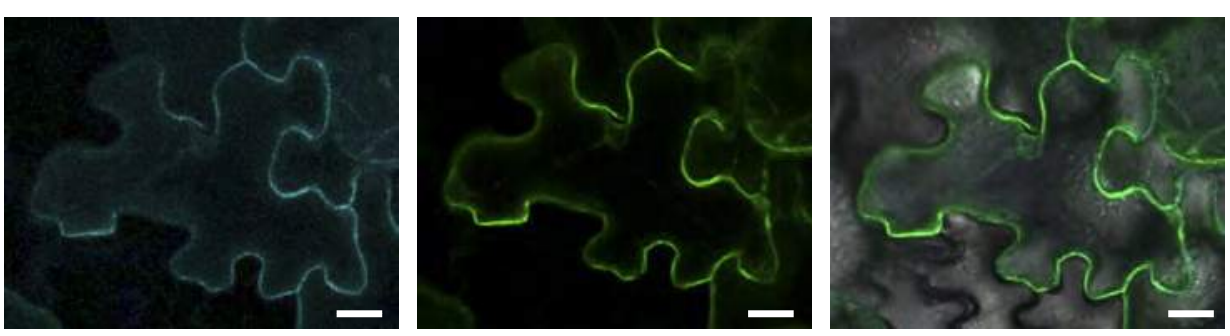

D

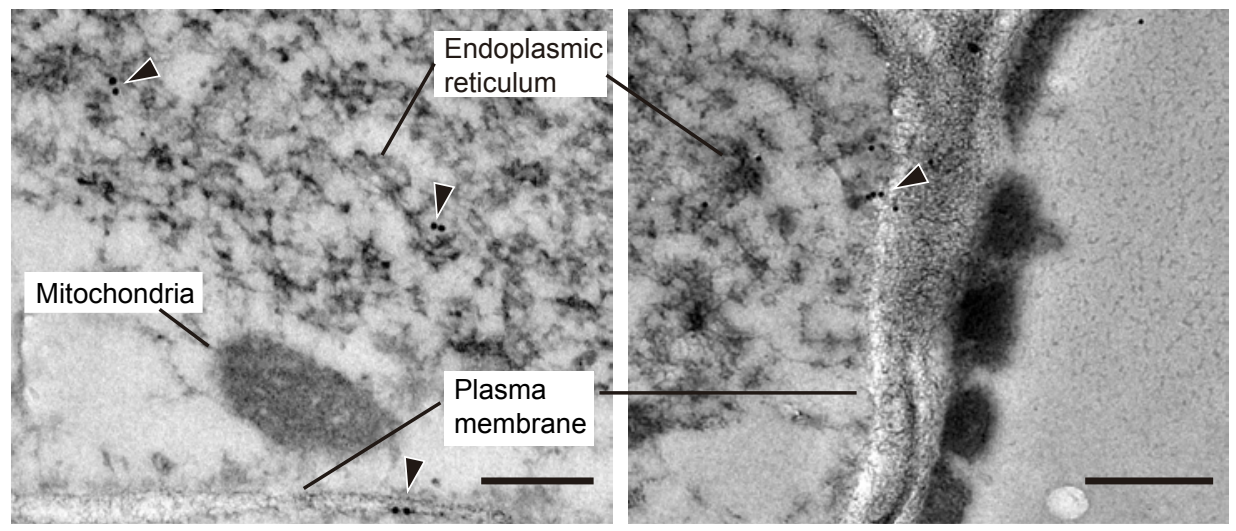


bioRxiv preprint doi: https://doi.org/10.1101/272112; this version posted February 28, 2018. The copyright holder for this preprint (which was not certified by peer review) is the author/funder, who has granted bioRxiv a license to display the preprint in perpetuity. It is made available under aCC-BY-NC-ND 4.0 International license.

Figure 4

A

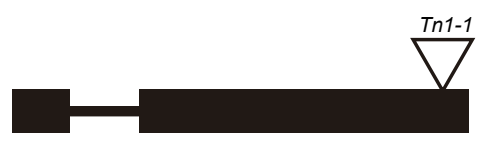

C

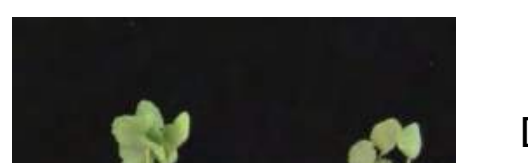

B

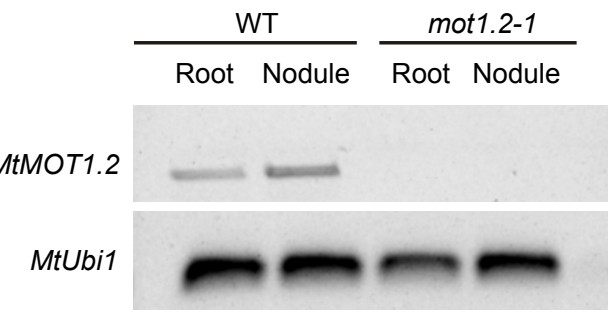

D

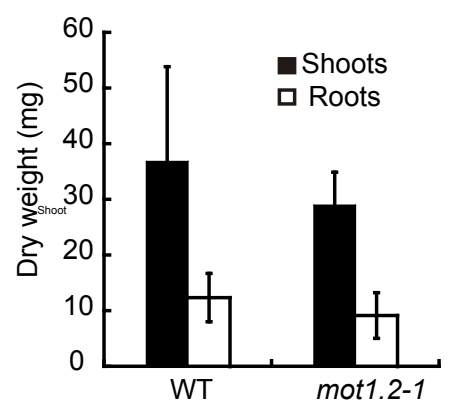

E

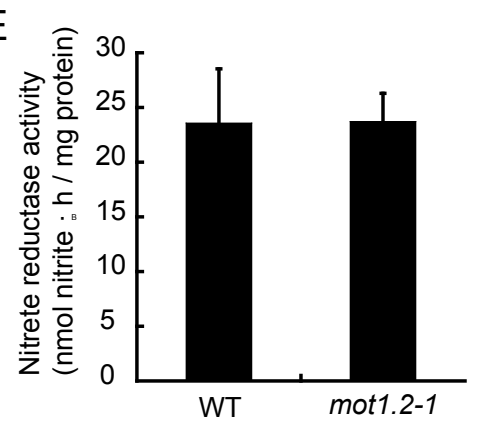


bioRxiv preprint doi: https://doi.org/10.1101/272112; this version posted February 28, 2018. The copyright holder for this preprint (which

was not certified by peer review) is the author/funder, who has granted bioRxiv a license to display the preprint in perpetuity. It is made available under aCC-BY-NC-ND 4.0 International license.

Figure 5

A

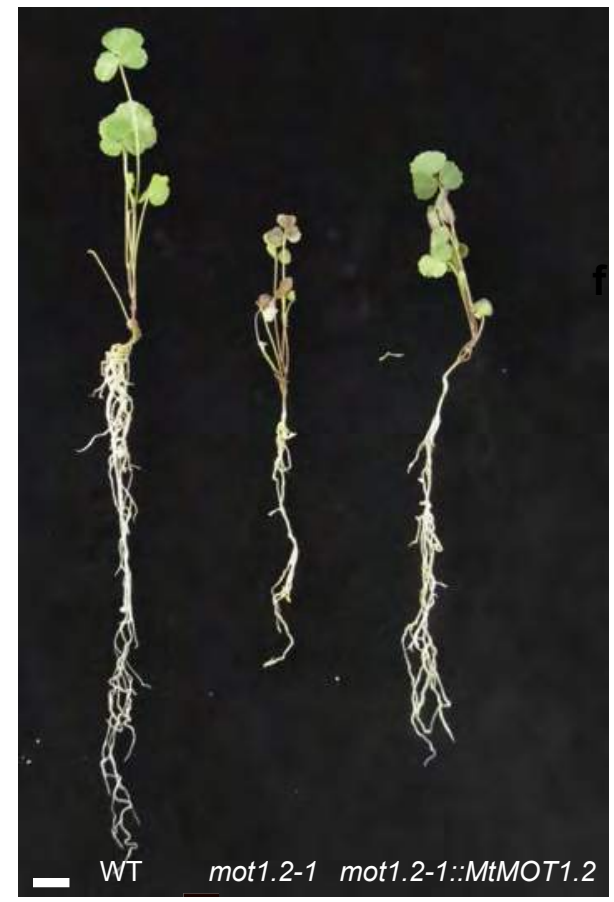

B

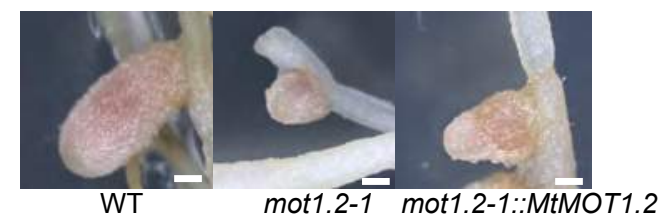

C

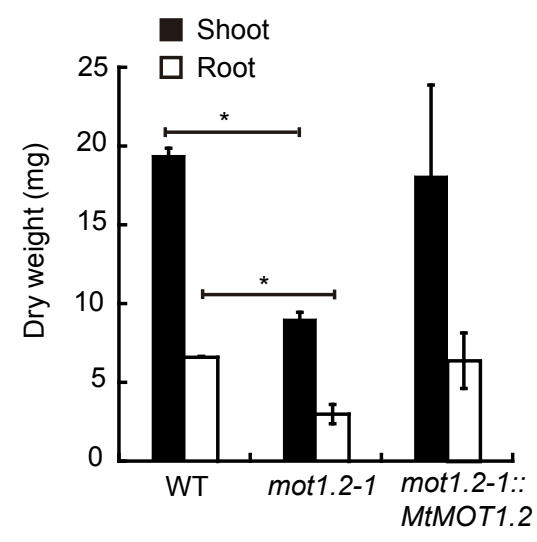

$\mathrm{D}$

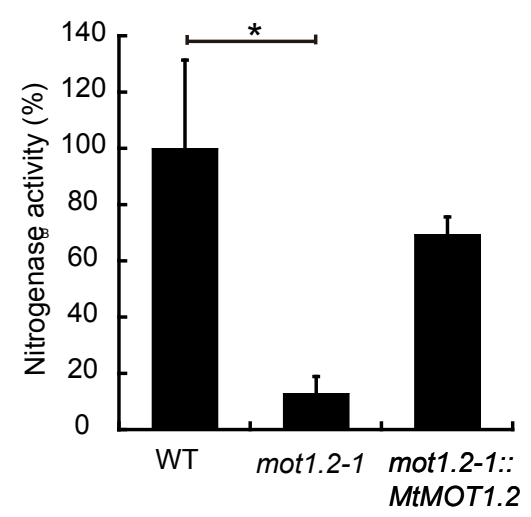

E

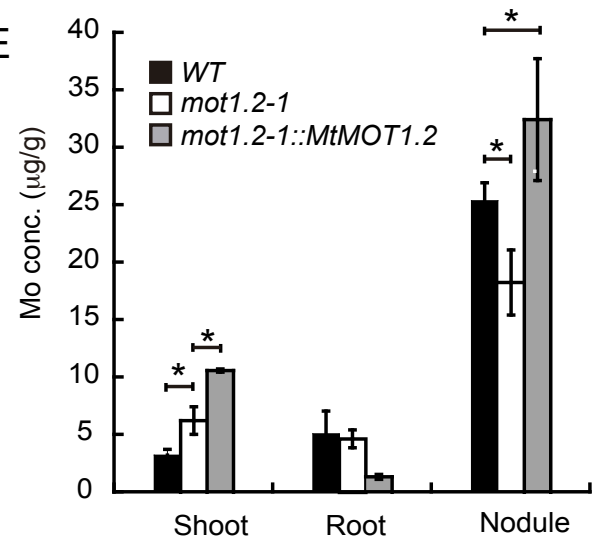


bioRxiv preprint doi: https://doi.org/10.1101/272112; this version posted February 28, 2018. The copyright holder for this preprint (which was not certified by peer review) is the author/funder, who has granted bioRxiv a license to display the preprint in perpetuity. It is made available under aCC-BY-NC-ND 4.0 International license.

Figure 6

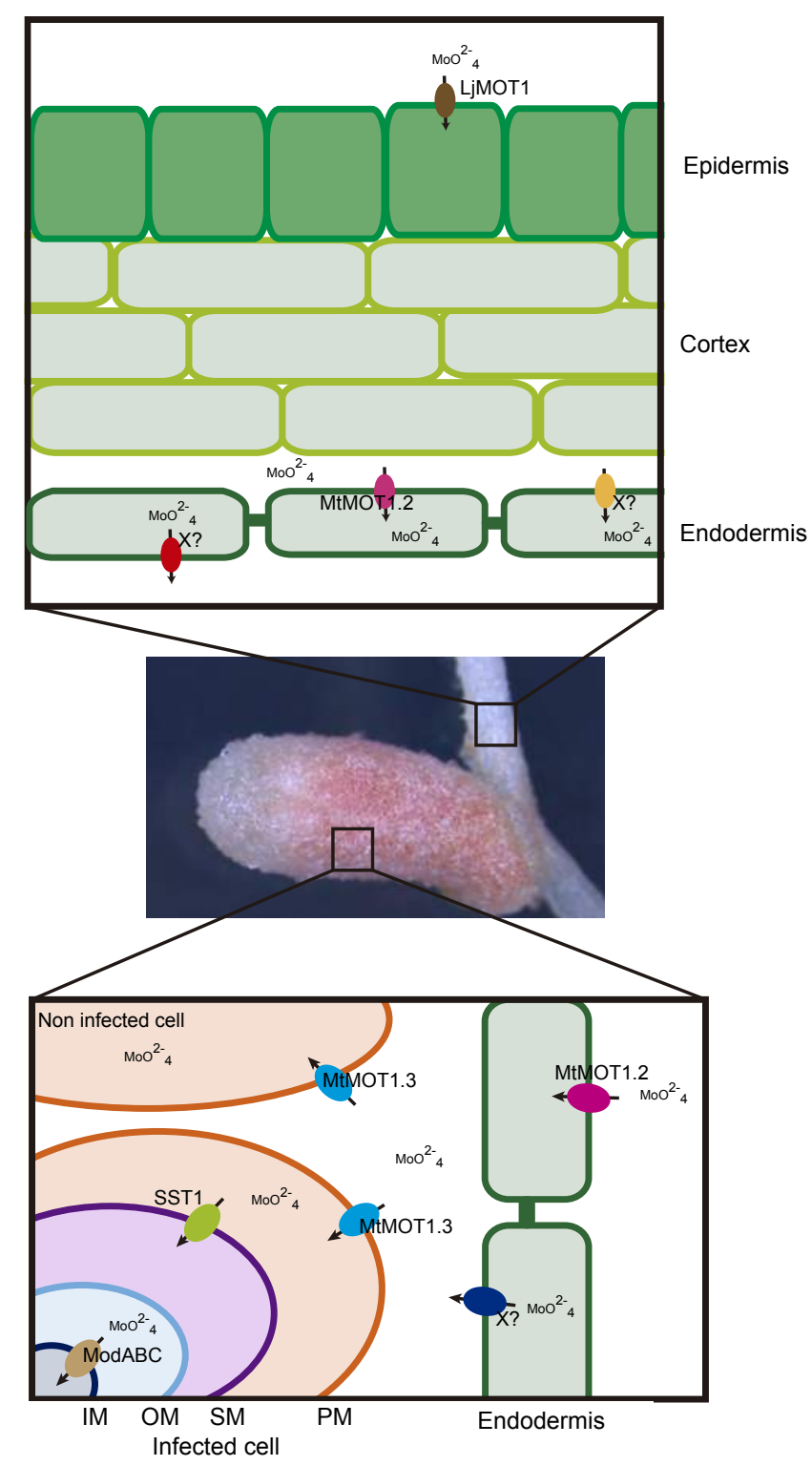

